\title{
Three-Component Assembly of Multiply Substituted Homoallylic Alcohols and Amines Using a Flow Chemistry Photoreactor
}

\author{
Yiding Chen, ${ }^{\dagger}$ David C. Blakemore, ${ }^{\dagger}$ Patrick Pasau, ${ }^{\S}$ a and Steven V. Ley, ${ }^{* \dagger}$ \\ ${ }^{\dagger}$ Department of Chemistry, University of Cambridge, Lensfield Road, Cambridge CB2 1EW, U.K. \\ ${ }^{\ddagger}$ Medicine Design, Pfizer Inc., Eastern Point Road, Groton, Connecticut 06340, United States \\ ${ }^{\S}$ UCB Biopharma SPRL, Chemical Research R5, Chemin du Foriest, 1420 Braine-L'Alleud, Belgium
}

Supporting Information

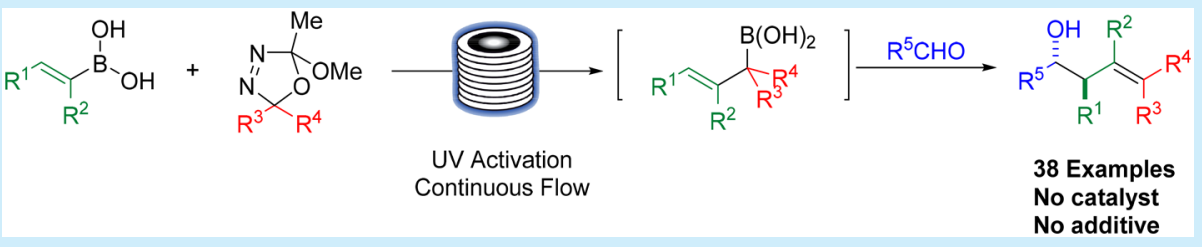

ABSTRACT: Oxadiazolines are bench-stable diazo precursors, which are activated under UV radiation in the presence of vinylboronic acids and aldehydes to enable a one-step three-component assembly of densely functionalized homoallylic alcohols. Substitution on all positions of the homoallylic alcohol product were achieved with high functional group tolerance. No catalyst or other additive was required to effect the reaction, which proceeds at $20^{\circ} \mathrm{C}$ over 40 min. Imines and indoles were also incorporated, giving access to homoallylic amines.

S ubstituted homoallylic alcohols are versatile and popular synthetic building blocks for the synthesis of valuable biologically active targets such as polyketides. ${ }^{1}$ Various routes to these materials have been introduced over the years, ${ }^{2}$ many of which employ allylboronates as a common intermediate due to the mildness and versatility of their reactions with carbonyl compounds. ${ }^{3}$ While significant progress has been made in the preparation of densely functionalized allylboronic acids and boronates, ${ }^{4}$ polysubstituted derivatives can be problematic owing to their instability (Figure 1). Therefore, new approaches for their preparation and the subsequent transformation into homoallylic alcohols are attractive. ${ }^{5}$ Herein, we report a three-component preparation of multiply substituted homoallylic alcohols via in situ generated allylboronic acid intermediates.

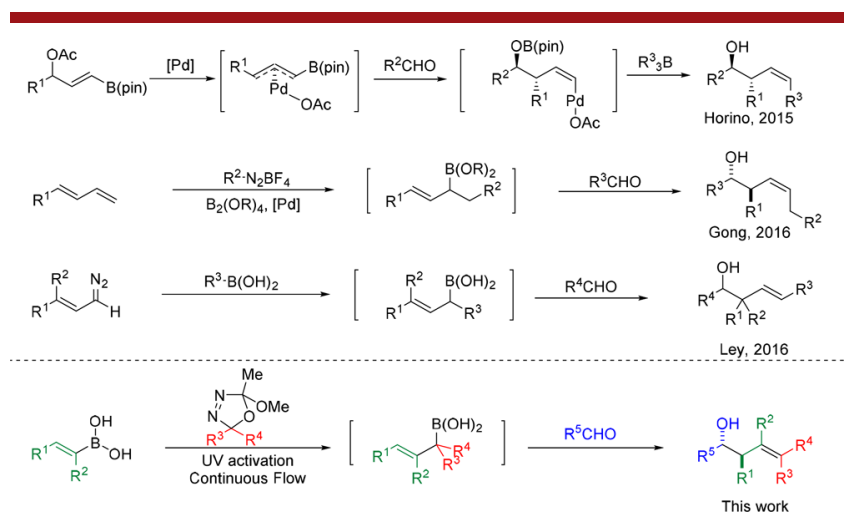

Figure 1. Selected examples of homoallylic alcohol synthesis via allylboronate intermediate.
Pioneering research by Warkentin et al. disclosed that under UV radiation around $300 \mathrm{~nm}$, 1,3,4-oxadiazolines undergo a photolysis process to give diazo compounds, many of which were not easily accessible via conventional diazo precursors such as hydrazones. ${ }^{6}$ Our recent work has revealed that these reactive nonstabilized diazo compounds generated via this pathway readily undergo $\mathrm{C}\left(\mathrm{sp}^{2}\right)-\mathrm{C}\left(\mathrm{sp}^{3}\right)$ cross-coupling reactions with arylboronic acids (Figure 2$){ }^{7}$ We anticipated

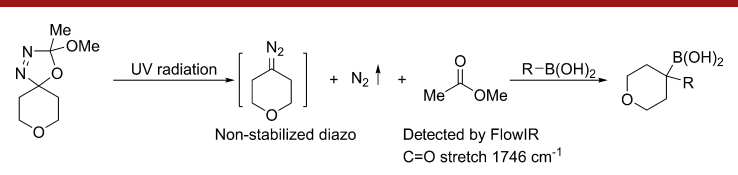

Figure 2. Nonstabilized diazo compound generated via UV activation of oxadiazoline, and their subsequent trap with boronic acid.

that a similar strategy could be applied to vinylboronic acids to generate highly substituted allylboronic acids in situ, and subsequently to afford functionalized homoallylic alcohol by a reaction with aldehydes.

To avoid potential buildup of hazardous quantities of diazo compounds, we commenced the investigation by irradiating a combination of oxadiazoline precursor (2) with styrylboronic acid (in equilibrium with boroxine) ${ }^{8}$ and 4-chlorobenzaldehyde using a flow reactor fitted with a UV irradiation source. ${ }^{9}$ As solvent, we used cyclopentylmethyl ether (CPME) as a greener alternative to tetrahydrofuran. ${ }^{10}$ Pleasingly, the first reaction gave a $42 \%$ yield of the desired product ( $4 a$ ) with the

Received: September 11, 2018

Published: October 1, 2018 
lamp power of $9 \mathrm{~W}$ (Table 1, entry 1). An improved yield of $82 \%$ was obtained by increasing the power of the lamp to $28 \mathrm{~W}$

Table 1. Optimization of the Three-Component Synthesis of Multisubstituted Homoallylic Alcohol ${ }^{a}$

$\begin{array}{clcccl}\text { entry } & \text { solvent } & \begin{array}{c}\text { lamp power } \\ (\mathrm{W})\end{array} & \begin{array}{c}\text { temp } \\ \left({ }^{\circ} \mathrm{C}\right)\end{array} & \begin{array}{c}\text { time } \\ (\mathrm{min})\end{array} & \text { yield (\%) } \\ 1 & \mathrm{CPME} & 9 & 20 & 40 & 42 \\ 2 & \mathrm{CPME} & 28 & 20 & 40 & 82(79)^{b} \\ 3^{c} & \mathrm{CPME} & 28 & 20 & 40 & 78 \\ 4^{d} & \mathrm{CPME}^{b} & 28 & 20 & 40 & 50 \\ 5 & \mathrm{CH}_{2} \mathrm{Cl}_{2}{ }^{e} & 28 & 20 & 40 & 0 \\ 6 & 2-\mathrm{MeTHF}^{c} & 28 & 20 & 40 & 43 \\ 7 & \mathrm{CPME} & 28 & 20 & 80 & 80 \\ 8 & \mathrm{CPME} & 28 & 20 & 20 & 51 \\ 9 & \mathrm{CPME} & 28 & 30 & 40 & 75 \\ 10 & \mathrm{CPME} & 28 & 10 & 40 & 37\end{array}$

${ }^{a}$ Reaction conditions: Styrylboronic acid (1.5 equiv, $0.075 \mathrm{M}$ ), oxadiazoline (1.5 equiv, $0.075 \mathrm{M}$ ), aldehyde (1.0 equiv, $0.05 \mathrm{M}$ ). NMR yield with 1,3,5-trimethoxybenzene as an internal standard. ${ }^{b}$ Isolated yield. ${ }^{c}$ With styrylboronic acid $(2.0$ equiv, $0.1 \mathrm{M})$ and oxadiazoline (2.0 equiv, $0.1 \mathrm{M}) .{ }^{d}$ With styrylboronic acid (1.0 equiv, $0.05 \mathrm{M}$ ) and oxadiazoline (1.0 equiv, $0.05 \mathrm{M}) .{ }^{e} 20 \mathrm{~mol} \%$ of DIPEA was added to assist solubilizing the boronic acid.

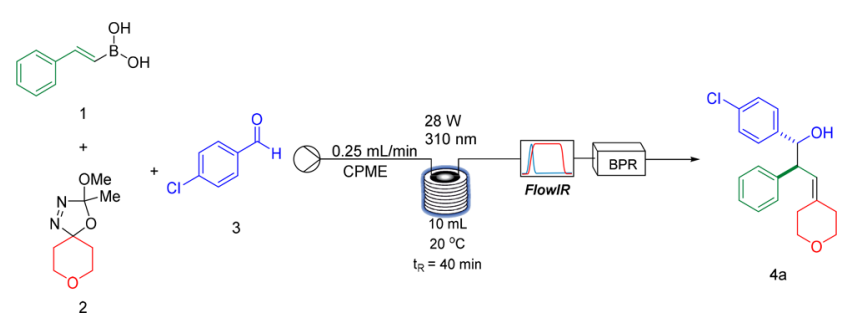

(entry 2). Varying the ratio of starting materials does not lead to any higher yield improvements (entry 3,4). Different solvents were examined such as 2-methyltetrahydrofuran or dichloromethane, which gave poorer results (entry 5, 6). Adjusting reaction time showed that $40 \mathrm{~min}$ irradiation time was sufficient to complete the reaction (entry 7,8 ). Increasing the reaction temperature to $30{ }^{\circ} \mathrm{C}$ resulted in slight loss of yield while cooling the reaction coil to $10{ }^{\circ} \mathrm{C}$ drastically reduced the yield of product to $37 \%$ (entry 9, 10). It is also worth noting that no trace of the other diastereoisomers were observed throughout the optimization process, with diastereoselectivity above 25:1 in all cases (for X-ray crystal structure of the reaction product, see Supporting Information).

With the optimal conditions in hand, we moved on to explore the scope of the method. A range of alkenyl boronic acids were well tolerated (Scheme 1). Styrylboronic acids represented by derivatives with different substitution of the benzene ring, all gave good yields of the corresponding homoallylic alcohols $(\mathbf{4 a - 4 f})$. It is worth noting that 4trifluoromethyl-styrylboronic acid offered little difference in reactivity, providing $70 \%$ yield (4f). Alkylvinyl boronic acids were tolerated under these conditions, producing the products in acceptable yields (4g and $\mathbf{4 h}$ ). Cyclopentenyl boronic acid showed comparable reactivity, generating product $4 \mathbf{i}$ in $63 \%$ yield. A gram-scale reaction was executed with chloromethylvinylboronic acid, which afforded $1.03 \mathrm{~g}$ of the targeted product with a consistent yield of $68 \%$, thus demonstrating the robustness of this method.
Scheme 1. Preparation of Multisubstituted Homoallylic Alcohols Using Various Vinyl Boronic Acids $1^{a}$

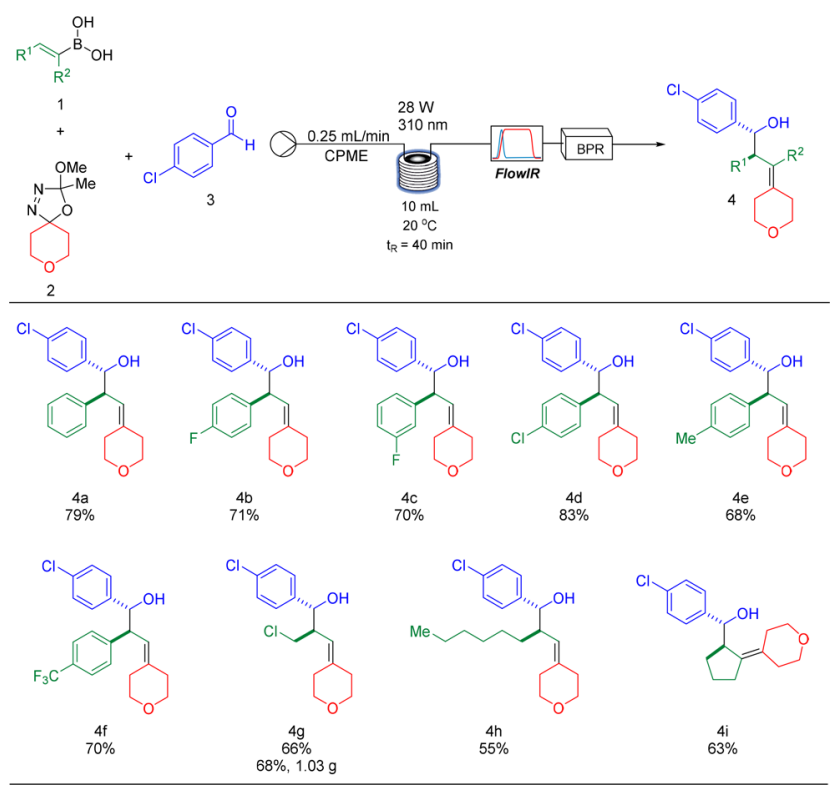

${ }^{a}$ Reaction conditions: $\mathbf{1}$ (1.5 equiv), $\mathbf{2}$ (1.5 equiv), 3 (1.0 equiv), 0.05 M. Isolated yields.

A variety of side chain substituents on the allylboronic acid intermediates were accomplished through the installation of the functionalized diazo compounds formed from various oxadiazoline precursors. Several oxadiazolines were prepared and examined (Scheme 2). Alkyl groups, including cyclopentyl and highly hindered adamantly groups all afforded good yields (4j and $4 \mathbf{k})$. Small-ring groups such as cyclobutyl, oxetanyl and azetidyl groups, were tolerated without reduction in yield (41$4 n$ ), demonstrating the mild nature of the reaction conditions.

Scheme 2. Preparation of Multisubstituted Homoallylic Alcohols Using Various Oxadiazolines $2^{a}$

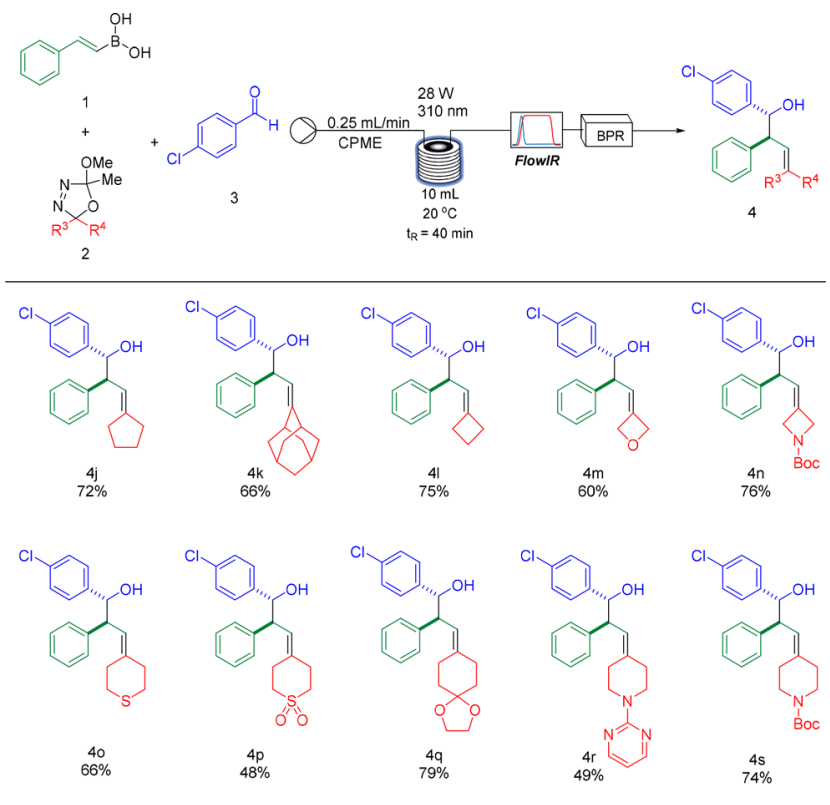

${ }^{a}$ Reaction conditions: 1 ( 1.5 equiv), 2 ( 1.5 equiv), 3 (1.0 equiv), 0.05 M. Isolated yields. 
Of the remaining substrates, both sulfide and sulfone were acceptable substrates (4o and $\mathbf{4 p}$ ), as well as the cyclohexyldioxolane compound $(\mathbf{4 q})$. Nitrogen containing functional groups featuring the $N$-pyrimidinylpiperidyl motif (4r) or $N$-boc piperidyl group (4s) were also incorporated efficiently, generating the related homoallylic alcohol products in $49 \%$ and $74 \%$ yields, respectively.

Next, we evaluated a diverse series of aldehydes as coupling partners (Scheme 3). Among these substituted aromatic

Scheme 3. Preparation of Multisubstituted Homoallylic Alcohols Using Various Aldehydes $3^{a}$

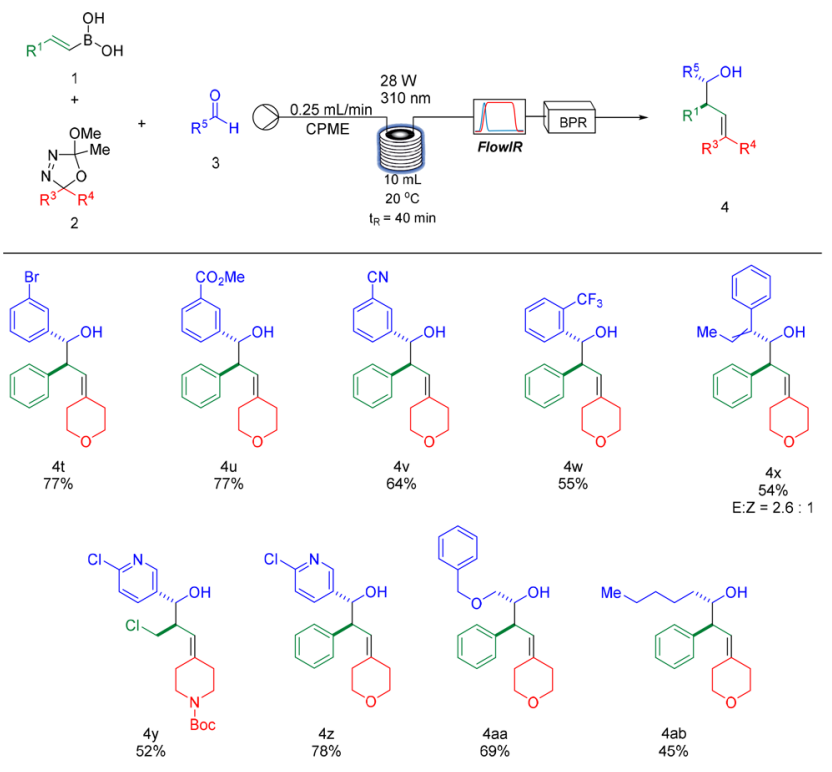

${ }^{a}$ Reaction conditions: 1 ( 1.5 equiv), 2 ( 1.5 equiv), 3 (1.0 equiv), 0.05 M. Isolated yields.

aldehydes, such as bromide (4t), ester (4u) and nitrile (4v) all proved tolerant to the reaction conditions. A particularly notable example was the use of 2-trifluoromethyl benzaldehyde, bearing both a strong electron-withdrawing group and a steric hindered substituent delivered a $55 \%$ of product $4 \mathbf{w}$. Reactive $\alpha, \beta$-unsaturated aldehyde showed a similar result and gave $54 \%$ yield of product $4 x$. Different reaction partners with 2-chloropyridyl aldehyde also generated the corresponding homoallylic alcohol in good yields (4y and $4 z$ ). Aliphatic aldehydes, although distinctively different electronically compared to aromatic derivatives, all reacted effectively. The examples included were benzoxyacetaldehyde and hexanal, both of which occurred in high yields (4aa and $4 \mathbf{a b}$ ).

While the broad range of substrates listed above have demonstrated the versatility of the methodology, compounds with strong $310 \mathrm{~nm}$ UV absorption bands could arguably affect the activation of oxadiazoline precursors. To address this problem, the reaction conditions were reassessed where we found a two-step approach to be optimal (Scheme 4). The reaction mixture containing vinylboronic acids was converted to the homoallylic precursor in the first step, and then subsequently reacted with the aldehydes coupling partner in a separate flask. This new approach substantially increases the diversity of the method. In addition to phenol substrate (4ac), other examples include several heterocyclic substrates such as thiophene (4ad), pyrimidine (4ae), pyrazine (4af), indazole
Scheme 4. Preparation of Multisubstituted Homoallylic Alcohols Using Various Aldehydes $3^{a}$

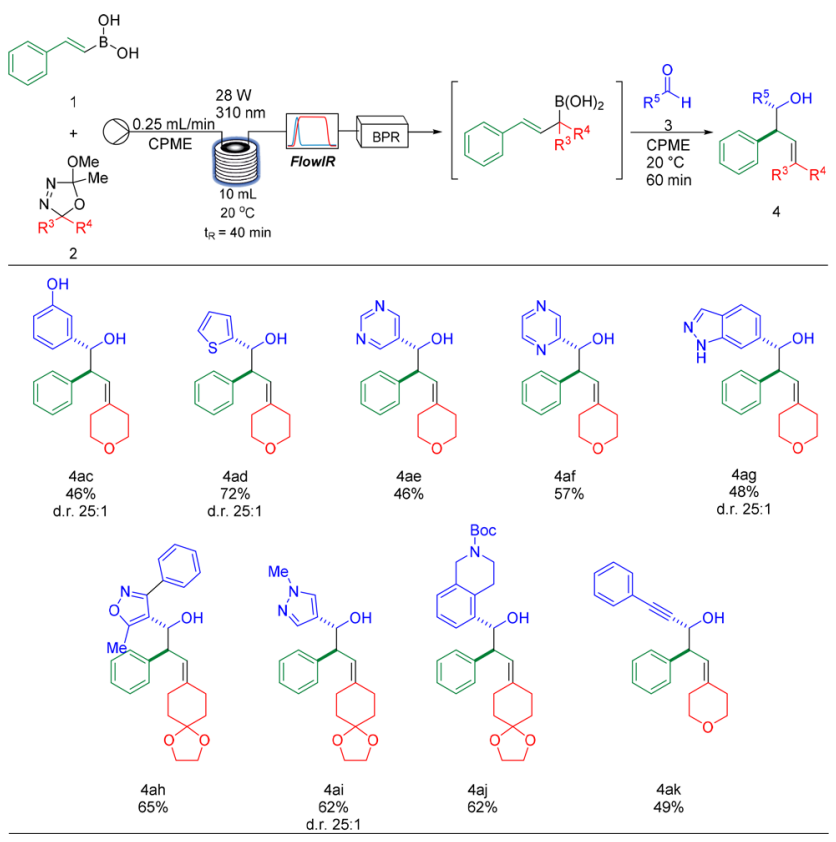

${ }^{a}$ Reaction conditions: 1 (1.5 equiv), 2 (1.5 equiv), $0.075 \mathrm{M}$; then 3 (1.0 equiv), $0.05 \mathrm{M}$. Isolated yields.

(4ag), isoxazole (4ah), and pyrazole (4ai), as well as tetrahydroisoquinoline (4aj) and propargyl aldehyde (4ak).

Additionally, incorporation of imine substrates ${ }^{11}$ and indoles $^{12}$ further expand the reaction scope, producing homoallylic amines as primary products (Scheme 5, 6a-6d).

Scheme 5. Preparation of Multisubstituted Homoallylic Amines Using Various Imines and Indole $5^{a}$
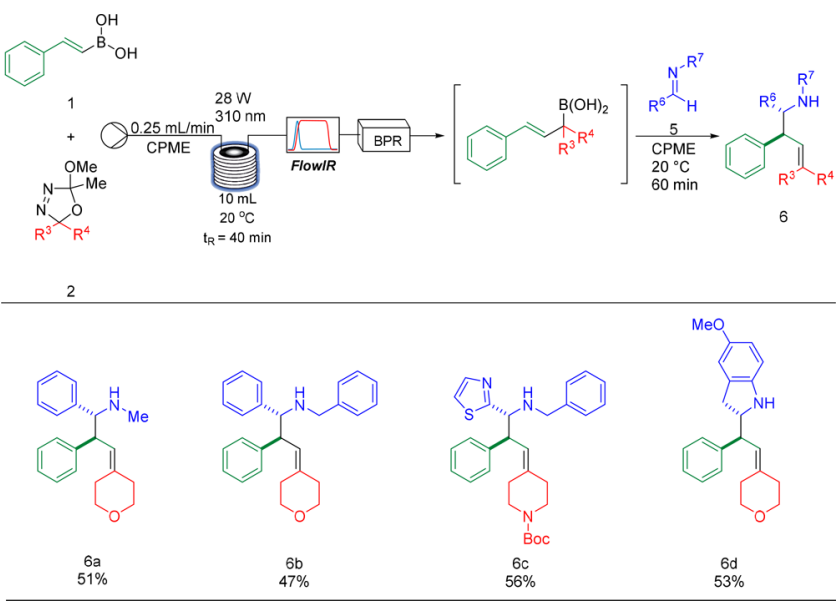

${ }^{a}$ Reaction conditions: 1 (1.5 equiv), 2 ( 1.5 equiv), $0.075 \mathrm{M}$; then 5 (1.0 equiv), $0.05 \mathrm{M}$. Isolated yields.

In conclusion, we report a new synthetic method toward polyfunctionalized homoallylic alcohols, with oxadiazolines as robust and efficient diazo precursors. The methodology utilized CPME as solvent and required no catalysts nor additives. The procedure was straightforward and was exemplified by a broad range of functional group tolerance in all reaction partners. 


\section{ASSOCIATED CONTENT}

\section{S Supporting Information}

The Supporting Information is available free of charge on the ACS Publications website at DOI: 10.1021/acs.orglett.8b02907.

Details of experimental procedure, compound characterization data and NMR spectra (PDF)

\section{Accession Codes}

CCDC 1867078 contains the supplementary crystallographic data for this paper. These data can be obtained free of charge via www.ccdc.cam.ac.uk/data_request/cif, or by emailing data_request@ccdc.cam.ac.uk, or by contacting The Cambridge Crystallographic Data Centre, 12 Union Road, Cambridge CB2 1EZ, UK; fax: +44 1223336033.

\section{AUTHOR INFORMATION}

\section{Corresponding Author}

*E-mail:svl1000@cam.ac.uk.

ORCID $\odot$

Yiding Chen: 0000-0001-6932-9005

Patrick Pasau: 0000-0002-1777-7911

Steven V. Ley: 0000-0002-7816-0042

Notes

The authors declare the following competing financial interest(s): D.C.B. is an employee and stockholder of Pfizer Inc.

Additional data related to this publication is available at the University of Cambridge Institutional Data Repository, https://doi.org/10.17863/CAM.26434.

\section{ACKNOWLEDGMENTS}

We thank Vapourtec Ltd and Duncan Guthrie for the generous loan of a flow UV reactor. The X-ray crystal structure was determined by Dr. Andrew D. Bond (University of Cambridge). Y. C. thanks Pfizer for funding the postdoctoral fellowship. The authors also gratefully acknowledge financial support from EPSRC (SVL; grant codes EP/K009494/1, EP/ $\mathrm{K} 039520 / 1$ and EP/M004120/1) and H2020-FETOPEN2016-2017 programme of European commission (SVL; grant agreement number: 737266-ONE FLOW).

\section{REFERENCES}

(1) (a) Sedgwick, D. M.; Grayson, M. N.; Fustero, S.; Barrio, P. Synthesis 2018, 50, 1935-1957. (b) Canterbury, D. P.; Micalizio, G. C. J. Am. Chem. Soc. 2010, 132, 7602-7604.

(2) (a) Komeyama, K.; Sakiyama, S.; Iwashita, K.; Osaka, I.; Takaki, K. Beilstein J. Org. Chem. 2018, 14, 1413-1420. (b) Chen, M.; Wei, Y.; Shi, M. Org. Chem. Front. 2018, 5, 2030-2034. (c) Tietze, L. F.; Kinzel, T.; Brazel, C. C. Acc. Chem. Res. 2009, 42, 367-378. (d) Denmark, S. E.; Weber, E. J. Helv. Chim. Acta 1983, 66, 16551660.

(3) (a) Hoffmann, R. W. Pure Appl. Chem. 1988, 60, 123-130. (b) Raducan, M.; Alam, R.; Szabó, K. J. Angew. Chem., Int. Ed. 2012, 51, 13050-13053. (c) Alam, R.; Vollgraff, T.; Eriksson, L.; Szabó, K. J. J. Am. Chem. Soc. 2015, 137, 11262-11265.

(4) (a) Diner, C.; Szabó, K. J. J. Am. Chem. Soc. 2017, 139, 2-14. (b) Kischkewitz, M.; Gerleve, C.; Studer, A. Org. Lett. 2018, 20, 3666-3669. (c) In Boronic Acids; Wiley: Weinheim. (d) Ryoto, K.; Sota, A.; Hajime, I. Angew. Chem., Int. Ed. 2018, 57, 7196-7199.

(5) (a) Horino, Y.; Aimono, A.; Abe, H. Org. Lett. 2015, 17, 28242827. (b) Tao, Z. L.; Adili, A.; Shen, H. C.; Han, Z. Y.; Gong, L. Z.
Angew. Chem., Int. Ed. 2016, 55, 4322-4326. (c) Battilocchio, C.; Feist, F.; Hafner, A.; Simon, M.; Tran, D. N.; Allwood, D. M.; Blakemore, D. C.; Ley, S. V. Nat. Chem. 2016, 8, 360.

(6) (a) Majchrzak, M. W.; Bekhazi, M.; Tse-Sheepy, I.; Warkentin, J. J. Org. Chem. 1989, 54, 1842-1845. (b) Pezacki, J. P.; Wagner, B. D.; Lew, C. S. Q.; Warkentin, J.; Lusztyk, J. J. Am. Chem. Soc. 1997, 119, 1789-1790. (c) Warkentin, J.; Woollard, J. M. R. Can. J. Chem. 1997, $75,289-307$.

(7) Greb, A.; Poh, J.-S.; Greed, S.; Battilocchio, C.; Pasau, P.; Blakemore, D. C.; Ley, S. V. Angew. Chem., Int. Ed. 2017, 56, 1660216605 .

(8) Bomio, C.; Kabeshov, M. A.; Lit, A. R.; Lau, S.-H.; Ehlert, J.; Battilocchio, C.; Ley, S. V. Chem. Sci. 2017, 8, 6071-6075.

(9) (a) Porta, R.; Benaglia, M.; Puglisi, A. Org. Process Res. Dev. 2016, 20, 2-25. (b) Yuanhai, S.; W, S. N. J.; Volker, H.; Timothy, N. Chem. - Eur. J. 2014, 20, 10562-10589.

(10) Watanabe, K.; Yamagiwa, N.; Torisawa, Y. Org. Process Res. Dev. 2007, 11, 251-258.

(11) (a) Alam, R.; Das, A.; Huang, G.; Eriksson, L.; Himo, F.; Szabó, K. J. Chem. Sci. 2014, 5, 2732-2738. (b) Ou, X.; Labes, R.; Battilocchio, C.; Ley, S. V. Org. Biomol. Chem. 2018, 16, 6652.

(12) Alam, R.; Diner, C.; Jonker, S.; Eriksson, L.; Szabó, K. J. Angew. Chem., Int. Ed. 2016, 55, 14417-14421. 